\title{
End of Frustration: Catalytic Precision Polymerization with Highly Interacting Lewis Pairs (HIPs)
}

Authors: Maximilian G. M. Knaus, ${ }^{a *}$ Marco M. Giuman, ${ }^{\mathrm{a} *}$ Alexander Pöthig ${ }^{\mathrm{b}}$ and Bernhard Rieger $^{\mathrm{a}}$

*These authors contributed equally to this work

‘Corresponding author. E-mail: rieger@tum.de

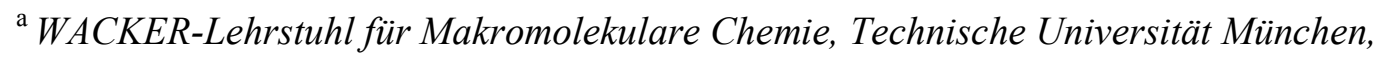
Lichtenbergstrase 4, 85748 Garching

${ }^{b}$ Technische Universität München, Catalysis Research Center,

Ernst-Otto-Fischer-Str. 1, D-85747 Garching b. München

\section{Materials and Methods:}

Unless otherwise stated, all chemicals were purchased from Sigma-Aldrich, VWRInternational or ABCR and used as received. Toluene and tetrahydrofuran were dried using an MBraun SPS-800 solvent purification system. $N, N$-dimethylformamide was dried over $\mathrm{CaH}_{2}$ (5\% w/v), distilled under reduced pressure and stored over $3 \AA$ molecular sieve.

Monomers were dried over $\mathrm{CaH}_{2}$ and destilled prior to use. NMR spectra were recorded on a Bruker AV-III-500 spectrometer equipped with a QNP-Cryoprobe or Bruker AV-III 300. ${ }^{1} \mathrm{H}$ NMR spectroscopic chemical shifts $\delta$ are reported in ppm relative to tetramethylsilane. $\delta\left({ }^{1} \mathrm{H}\right)$ is calibrated to the residual proton signal of the solvent. Deuterated solvents were obtained from Eurisotop or Sigma Aldrich. Elemental analyses were measured at the Laboratory for Microanalytics at the Institute of Inorganic Chemistry at the Technische Universität München. 
GPC was carried out on a Varian LC-920 equipped with two PL Polargel columns or Varian PL GPC-50 equipped with two PLgelMixed C. As eluents $N, N$-dimethylformamide $(25 \mathrm{mM}$ $\mathrm{LiBr})$, tetrahydrofuran/water $(1: 1,9 \mathrm{~g} / \mathrm{L}$ tetrabutylammonium bromide) or tetrahydrofuran were used. Absolute molecular weights have been determined by two angle (Varian PL GPC50) or multiangle laser light scattering (MALLS) analysis (LC-920) using a Wyatt Dawn Heleos II in combination with a Wyatt Optilab rEX as concentration detector, coupled with GPC.

Micro-GC analysis was performed by using a Varian 490 gas chromatograph equipped with a $1 \mathrm{~m} \mathrm{COX} \mathrm{column}$ and a GCthermal conductivity detector. He(5.0) was used as the carrier gas.

\section{General procedure for the polymerization of acrylic monomers}

Polymerizations were performed in $30 \mathrm{~mL}$ oven-dried glass reactors interfaced to a dualmanifold Schlenk line at various temperatures under argon atmosphere. A predetermined amount of a Lewis acid in toluene was first dissolved in the solvent. Then the polymerization was started by sequential addition of monomer $(0.5 \mathrm{~mL})$ and a predetermined amount of phosphine via a gastight syringe under vigorous stirring (direct addition of Lewis acid base adduct to a solution of monomer in the corresponding solvent led to comparable results). After the measured time interval, a $0.2 \mathrm{~mL}$ aliquot was taken from the reaction mixture via a syringe and quickly quenched into a $4 \mathrm{~mL}$ vial containing $0.6 \mathrm{~mL}$ of undried "wet" $\mathrm{CDCl}_{3} / \mathrm{DMSO}-\mathrm{d}_{6} / \mathrm{MeOD}-\mathrm{d}_{4}$. The quenched aliquots were later analyzed by ${ }^{1} \mathrm{H}$ NMR to obtain the polymer yield data. The polymerization was immediately quenched after the removal of the aliquot by addition of $5 \mathrm{~mL} \mathrm{5 \%} \mathrm{HCl}$-acidified/aqueous methanol. The quenched mixtures were precipitated, stirred for $1 \mathrm{~h}$, filtered, washed with solvent and dried in a vacuum oven at $50{ }^{\circ} \mathrm{C}$ overnight to a constant weight to verify the polymer yields determined by ${ }^{1} \mathrm{H}$ NMR. 


\section{Characterization of Synthesized Organometallic Compounds}

\section{Synthesis of triphenylaluminum-trimethylphosphine adduct}

To a solution of triphenylaluminium $(100 \mathrm{mg}, 258 \mu \mathrm{mol})$ in toluene $(2 \mathrm{~mL})$ trimethylphosphine $(0.5 \mathrm{~mL})$ was added at $-78^{\circ} \mathrm{C}$. The solvent and excess trimethylphosphine were removed under high vacuum. Crystals suitable for single X-ray analysis could be obtained out of a toluene / pentane solution at $-30^{\circ} \mathrm{C}$ via a vapor diffusion technique.

${ }^{1} \mathrm{H}$ NMR (500 MHz, $\left.\mathrm{CD}_{2} \mathrm{Cl}_{2}, 298 \mathrm{~K}\right): 7.77$ (m, 6H, Ar- $H$ ), 7.36 (m, 9H, Ar- $H$ ), 1.22 (d, $J=7.5$ $\left.\mathrm{Hz}, 9 \mathrm{H}, \mathrm{CH}_{3}\right)$.

${ }^{31} \mathrm{P}$ NMR (121 MHz, $\left.\mathrm{CD}_{2} \mathrm{Cl}_{2}, 298 \mathrm{~K}\right):-48.4$ (s).

${ }^{13} \mathrm{C}$ NMR (75 MHz, $\left.\mathrm{CD}_{2} \mathrm{Cl}_{2}, 298 \mathrm{~K}\right): 127.2$ (6C, o-C), 127.4 (3C, $p$-C), 128.3 (3C, $i$-C), 138.3 (6C, $m-\mathrm{C}), 10.40\left(\mathrm{~d}, J=20.4 \mathrm{~Hz}, 3 \mathrm{C}, \mathrm{CH}_{3}\right)$.

A clear pale yellow fragment-like specimen of $\mathrm{C}_{21} \mathrm{H}_{24} \mathrm{AlP}$, approximate dimensions $0.066 \mathrm{~mm}$ x $0.086 \mathrm{~mm} \times 0.330 \mathrm{~mm}$, was used for the X-ray crystallographic analysis. The X-ray intensity data were measured on a Bruker Kappa APEX II CCD system equipped with a MONTEL mirror monochromator and a Mo FR591 rotating anode $(\lambda=0.71073 \AA)$. A total of 2120 frames were collected. The total exposure time was 5.89 hours. The frames were integrated with the Bruker SAINT software package using a narrow-frame algorithm. The integration of the data using a trigonal unit cell yielded a total of 13376 reflections to a maximum $\theta$ angle of $27.10^{\circ}(0.78 \AA$ resolution), of which 1396 were independent (average redundancy 9.582, completeness $\left.=100.0 \%, \mathrm{R}_{\text {int }}=6.24 \%, \mathrm{R}_{\text {sig }}=4.32 \%\right)$ and $1305(93.48 \%)$ were greater than $2 \sigma\left(F^{2}\right)$. The final cell constants of $\underline{a}=12.0529(10) \AA, \underline{b}=12.0529(10) \AA$, $\underline{c}$ $=7.4996(7) \AA$, volume $=943.52(18) \AA^{3}$, are based upon the refinement of the XYZ-centroids of 5933 reflections above $20 \sigma(\mathrm{I})$ with $6.690^{\circ}<2 \theta<56.36^{\circ}$. Data were corrected for absorption effects using the multi-scan method (SADABS). The ratio of minimum to maximum apparent transmission was 0.858 . The calculated minimum and maximum transmission coefficients (based on crystal size) are 0.9400 and 0.9880 . The final anisotropic 
full-matrix least-squares refinement on $\mathrm{F}^{2}$ with 72 variables converged at $\mathrm{R} 1=3.84 \%$, for the observed data and wR2 $=9.49 \%$ for all data. The goodness-of-fit was 1.078 . The largest peak in the final difference electron density synthesis was $0.300 \mathrm{e}^{-} / \AA^{3}$ and the largest hole was $0.203 \mathrm{e}^{-} / \AA^{3}$ with an RMS deviation of $0.036 \mathrm{e}^{-} / \AA^{3}$. On the basis of the final model, the calculated density was $1.177 \mathrm{~g} / \mathrm{cm}^{3}$ and $\mathrm{F}(000), 356 \mathrm{e}^{-}$.

CCDC 1475818 contains the supplementary crystallographic data for this paper. These data can be obtained free of charge from The Cambridge Crystallographic Data Centre via www.ccdc.cam.ac.uk/data request/cif.

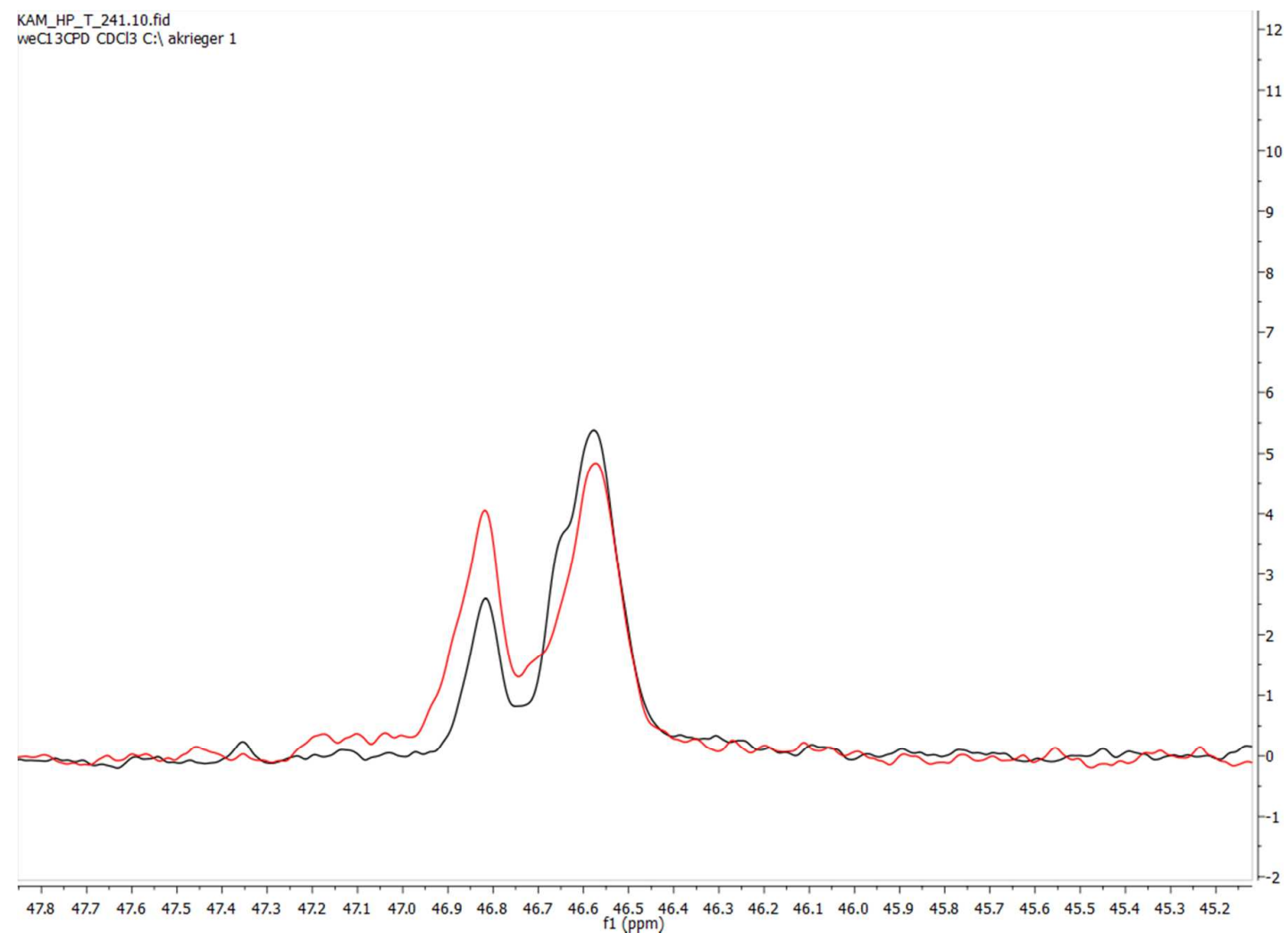

Figure S1. ${ }^{13} \mathrm{C}-\mathrm{NMR}\left(75 \mathrm{MHz}, \mathrm{CDCl}_{3}, 298 \mathrm{~K}\right)$ spectra of entry 1 and 2 of table 2 (red entry 1, black entry 2). 


\section{Kinetic Studies}

According to quantum chemical calculations chain initiation is the rate-determining step in conjugate-addition polymerization. ${ }^{[1]}$

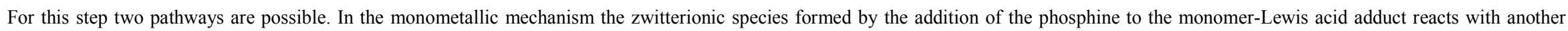
MMA molecule, whereas in the bimetallic mechanism the second MMA is activated by another Lewis acid. To gain a deeper understanding which mechanism is taking place, we performed kinetic analysis of the reaction.

The general rate law for catalyzed polymerizations reads (1):

$$
r=k x[\text { Cat. }]^{m} x[M]^{n}(1)
$$

In the case of the conjugate-addition polymerization reads (2):

$$
r=k x[\text { Cat. }]^{m 1} x[I]^{m 2} x[M]^{n}(2)
$$

Since excess phosphine leads to quenching of the catalytic aluminum center, direct determination of the order in catalyst is not possible. As a consequence we determined the overall reaction order in catalyst and initiator by keeping the $\mathrm{Al} / \mathrm{P}$ ratio constant at 0.5 and vary the catalyst to monomer ratio. Subsequently we determined the order in initiator. Assuming that summation of reaction orders $\mathrm{m} 1+\mathrm{m} 2$ is linear, you can calculate the order in aluminum catalyst $(\mathrm{m} 1)$ as the difference of these two orders. For different catalyst concentrations of otherwise identical reaction conditions, the maximum rate is consistently reached at similar conversions $(<10 \%)$. Therefore, the residual monomer concentration is assumed to be constant. Rate law for this reaction reads $(3)$.

$$
r=k x[\text { Cat. }]^{m 1} x[I]^{m 2}(3)
$$

The plot of $\ln (r)$ against $\ln ([\mathrm{Cat}])$ yields a reaction order of $m=\mathrm{m} 1+\mathrm{m} 2=3$ (Figure S2).

For determination of order in initiator according to equation (4), reaction rate was measured for different phosphine concentrations.

$$
r=k \times[I]^{n}(4)
$$

Plotting $\ln (r)$ against $\ln ([\mathrm{P}])$ gave the order in initiator $n=1$ (Figure S3).

These results clearly show that the Lewis pair mediated conjugate-addition polymerization follows a bimetallic chain initiation mechanism, initiated by a reaction first order in initiating phosphine. This conclusion is in line with theoretical calculations. ${ }^{[1]}$ Contrary to the frustrated Lewis pair polymerization of Chen et al., we could not observe any induction period as evidenced by the reaction kinetics shown in figure $\mathrm{S} 5$. 
Table S1: Determination of catalyst+initiator order $\mathrm{AlPh}_{3} \mathrm{PMe}_{3}$, methylmethacrylate, toluene, $30^{\circ} \mathrm{C}$.

\begin{tabular}{|ccccccc|}
\hline Monomer/Cat & {$[\mathrm{P}] /[\mathrm{Al}]$} & $\mathbf{n}($ Cat) $[\mathrm{mol}]$ & $\mathbf{c}\left(\right.$ Cat) $\left[\mathrm{mol} \mathrm{L}^{-1}\right.$ ] & $\ln [\mathbf{c}($ Cat)] & rate $\left[\mathrm{mol} \mathrm{L}^{-1} \mathbf{s}^{-1]}\right.$ & $\ln (\mathrm{rate})$ \\
\hline 112.5 & 0.5 & $2.89184 \mathrm{E}-05$ & 0.00723 & -4.9296 & 0.0177 & -4.0342 \\
125 & 0.5 & $2.60266 \mathrm{E}-05$ & 0.00651 & -5.0349 & 0.0119 & -4.4312 \\
150 & 0.5 & $2.16888 \mathrm{E}-05$ & 0.00542 & -5.2173 & 0.0076 & -4.8796 \\
162.5 & 0.5 & $2.00204 \mathrm{E}-05$ & 0.00501 & -5.2973 & 0.0056 & -5.1850 \\
\hline
\end{tabular}

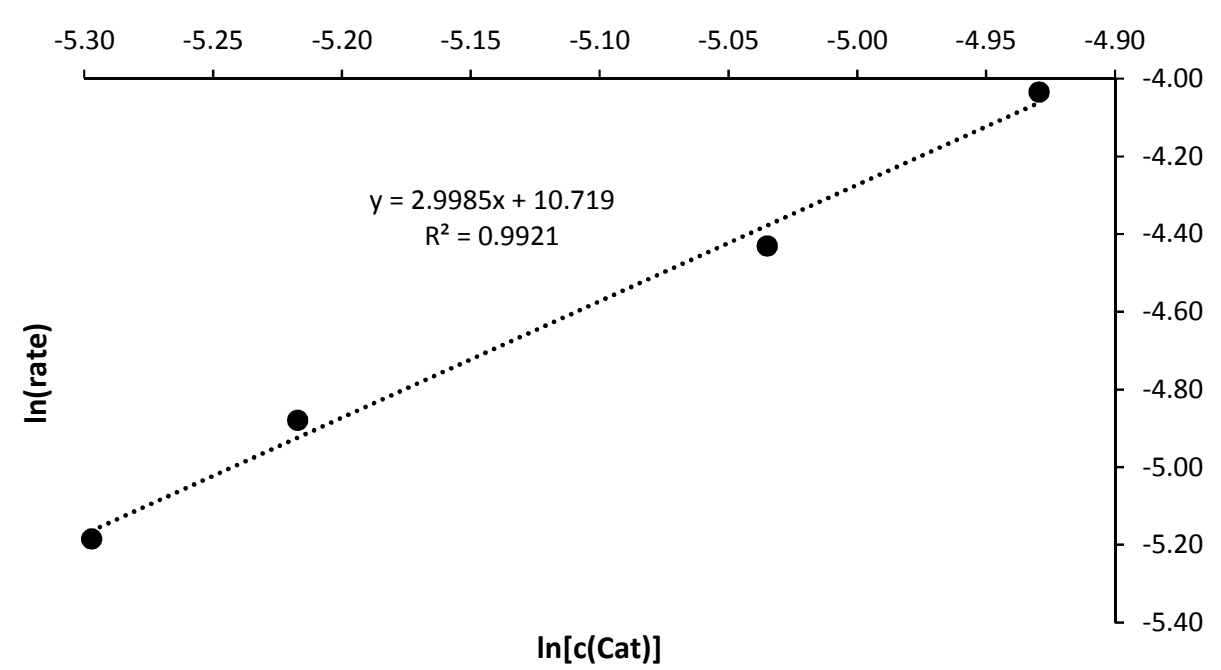

Figure S2: Determination of catalyst+initiator order $\mathrm{AlPh}_{3} \mathrm{PMe}_{3}$, methylmethacrylate, toluene, $30^{\circ} \mathrm{C}$. 
Table S2: Determination of initiator order $\mathrm{AlPh}_{3} \mathrm{PMe}_{3}$, methylmethacrylate, toluene, $30^{\circ} \mathrm{C}$.

\begin{tabular}{|ccccccc|}
\hline Monomer/P & {$[\mathbf{P}] /[\mathrm{Al}]$} & $\mathbf{n}(\mathbf{P})[\mathrm{mol}]$ & $\mathbf{c}(\mathbf{P})\left[\mathrm{mol} \mathrm{L}^{-1}\right]$ & $\ln [\mathbf{c}(\mathbf{P})]$ & rate $\left[\mathrm{mol} \mathrm{L}^{-1} \mathbf{s}^{-1}\right]$ & $\ln (\mathbf{r a t e})$ \\
\hline 100 & 0.508 & $3.25332 \mathrm{E}-05$ & 0.00813 & -4.8118 & 0.0102 & -4.5854 \\
112.5 & 0.452 & $2.89184 \mathrm{E}-05$ & 0.00723 & -4.9296 & 0.009 & -4.7105 \\
125 & 0.407 & $2.60266 \mathrm{E}-05$ & 0.00651 & -5.0349 & 0.0083 & -4.7915 \\
150 & 0.339 & $2.16888 \mathrm{E}-05$ & 0.00542 & -5.2173 & 0.0065 & -5.0360 \\
\hline
\end{tabular}

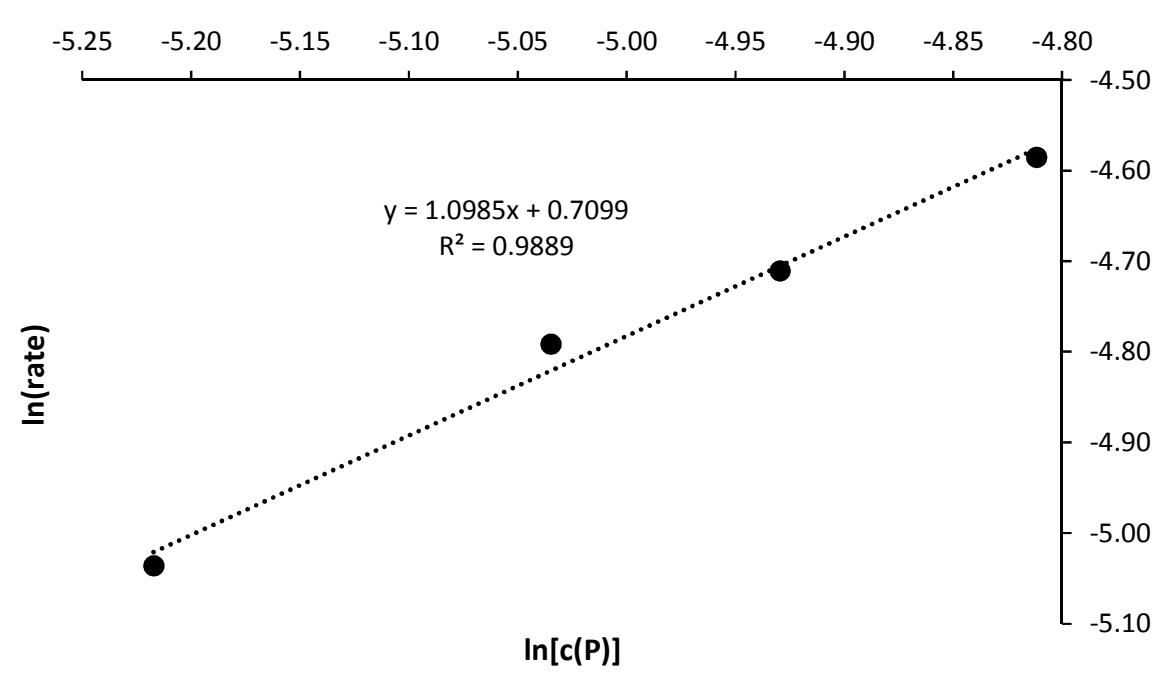

Figure S3: Determination of initiator order $\mathrm{AlPh}_{3} \mathrm{PMe}_{3}$, methylmethacrylate, toluene, $30^{\circ} \mathrm{C}$. 
Table S3: Micro-GC experiments of DEVP polymerizations with different catalyst loadings.

\begin{tabular}{|ccccccc|}
\hline entry & Catalyst pair & {$[\mathrm{P}] /[\mathrm{Al}]$} & Al/monomer & Temperature & Time & Area [uV.min] \\
\hline 1 & $\mathrm{Al}(\mathrm{Ph})_{3}+\mathrm{PMe}_{3}$ & 0.5 & 10 & $\mathrm{RT}$ & 60 & 13133 \\
2 & $\mathrm{Al}(\mathrm{Ph})_{3}+\mathrm{PMe}_{3}$ & 0.5 & 5 & $\mathrm{RT}$ & 60 & 12789 \\
\hline
\end{tabular}

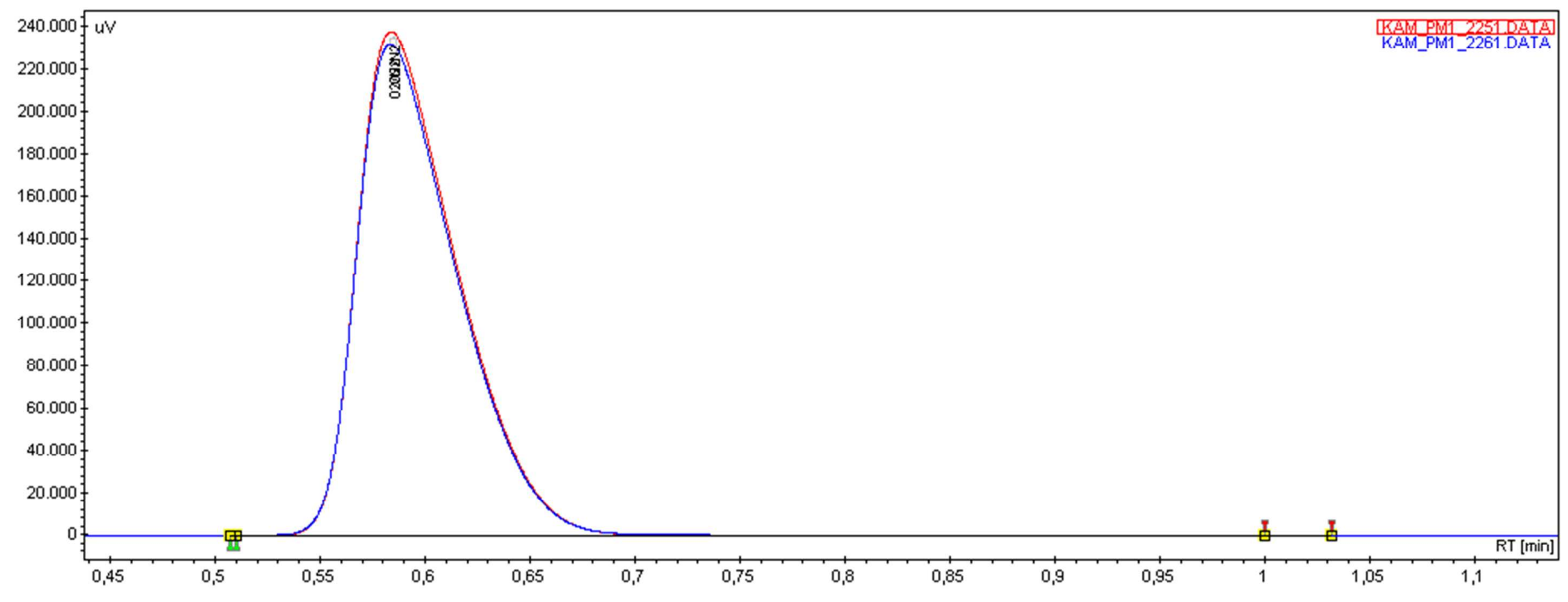

Figure S4: Micro-GC measurements of DEVP polymerizations with different catalyst loadings (red entry 1, blue entry 2). 


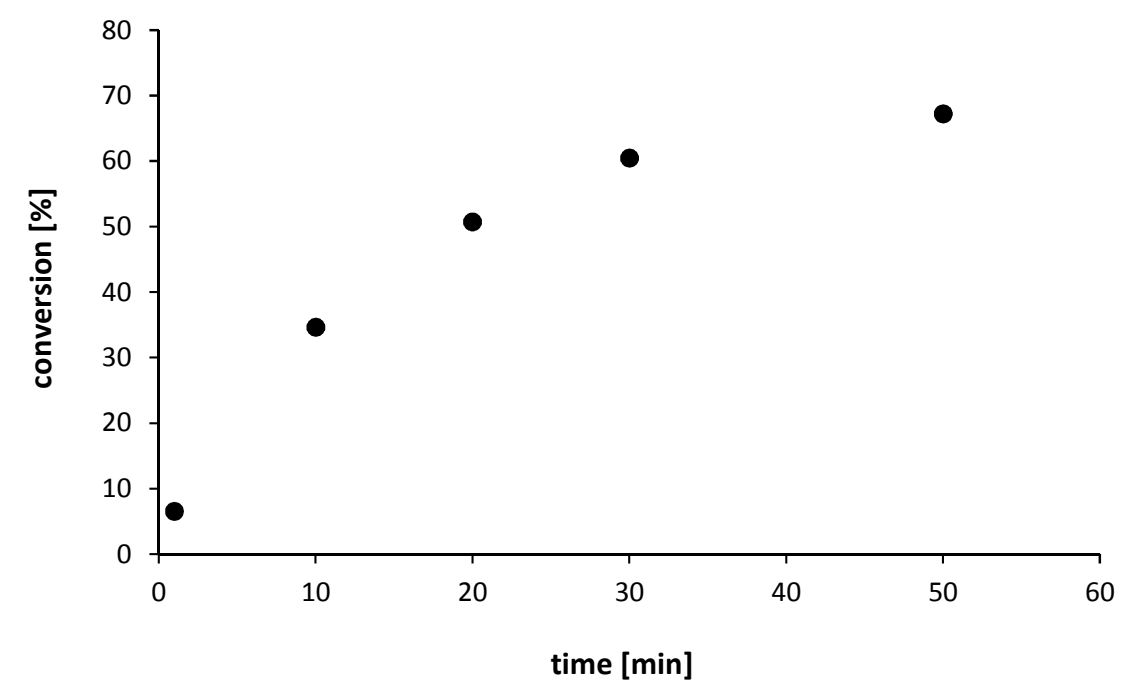

Figure S5: Time vs. conversion plot for polymerization of furfurylmethacrylate with $\mathrm{AlPh}_{3} / \mathrm{PEt}_{3}(200: 1: 0.5)$. 


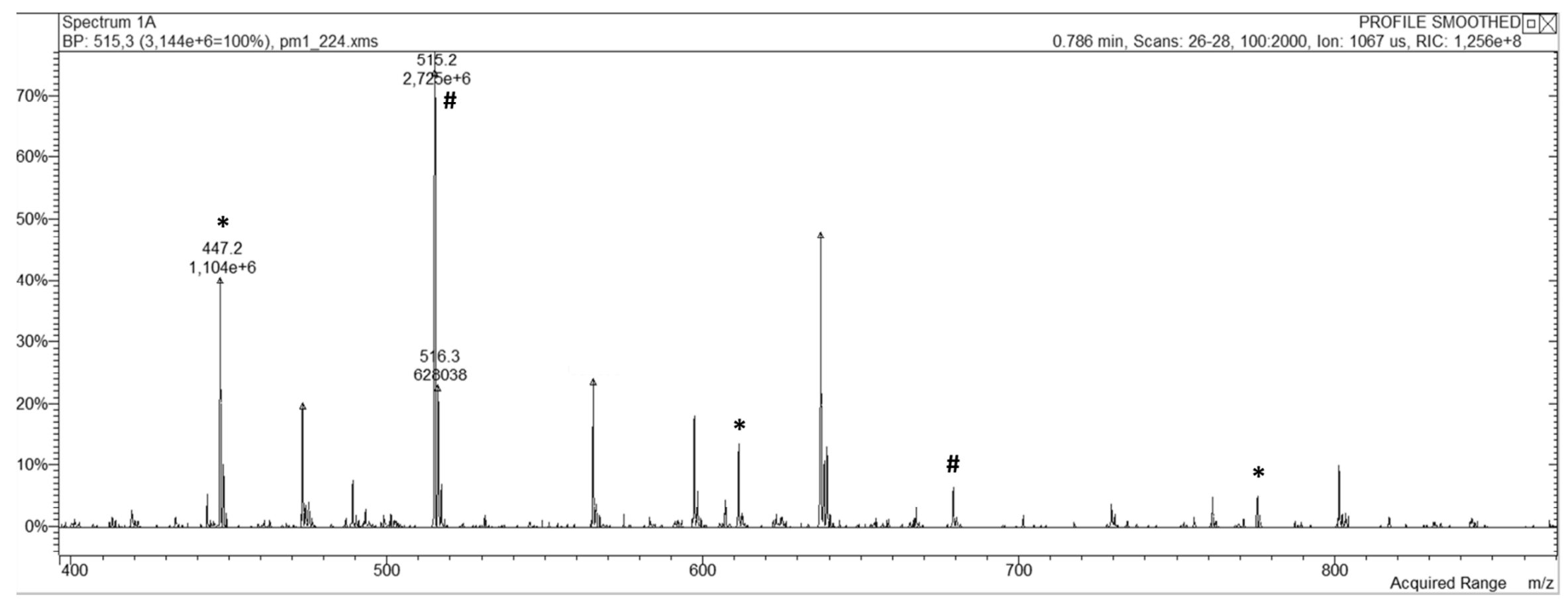

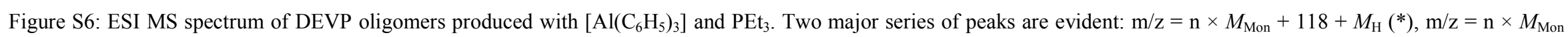

$+M_{\mathrm{H}}(\#) ; M_{\mathrm{Mon}}=164$, end groups: $M_{\mathrm{PEt}_{3}}=118$. 


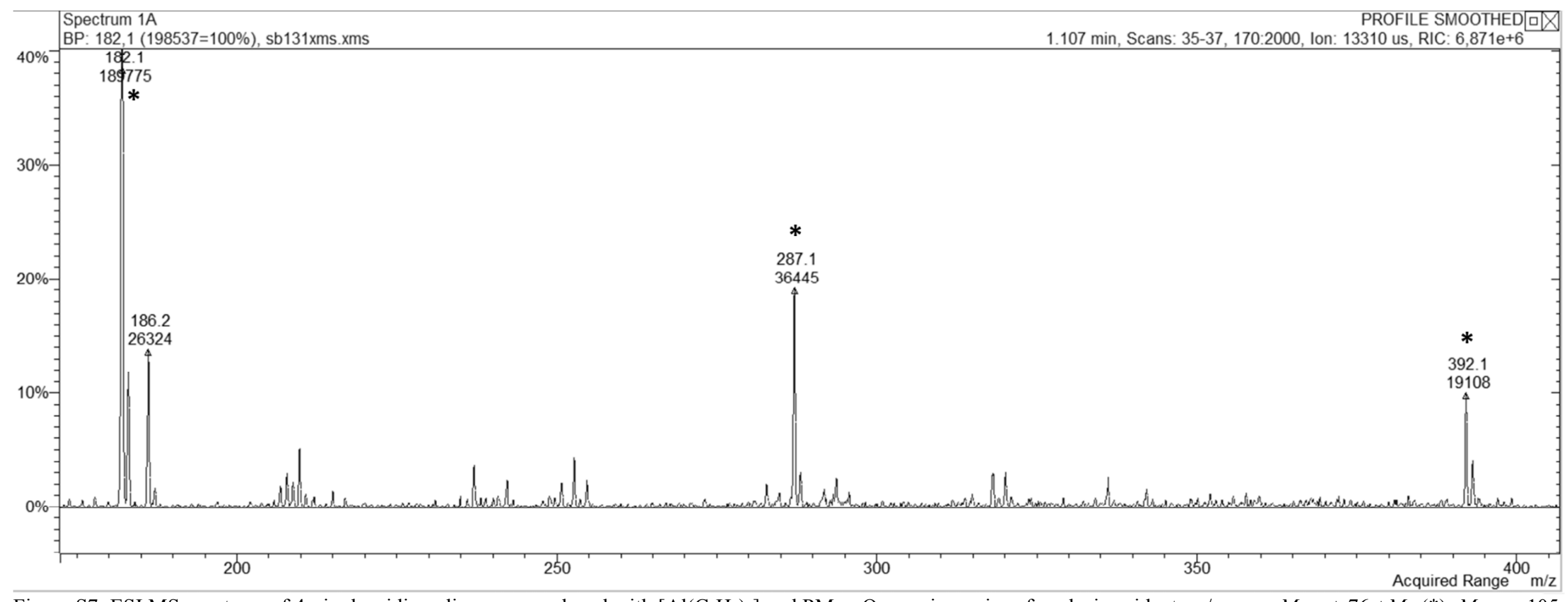

Figure S7: ESI MS spectrum of 4-vinylpyridine oligomers produced with $\left[\mathrm{Al}\left(\mathrm{C}_{2} \mathrm{H}_{5}\right)_{3}\right]$ and $\mathrm{PMe}_{3}$. One major series of peaks is evident: $\mathrm{m} / \mathrm{z}=\mathrm{n} \times M_{\text {Mon }}+76+M_{\mathrm{H}}(*) ; M_{\mathrm{Mon}}=105$,

end groups: $M_{\mathrm{PMe}_{3}}=76$ 


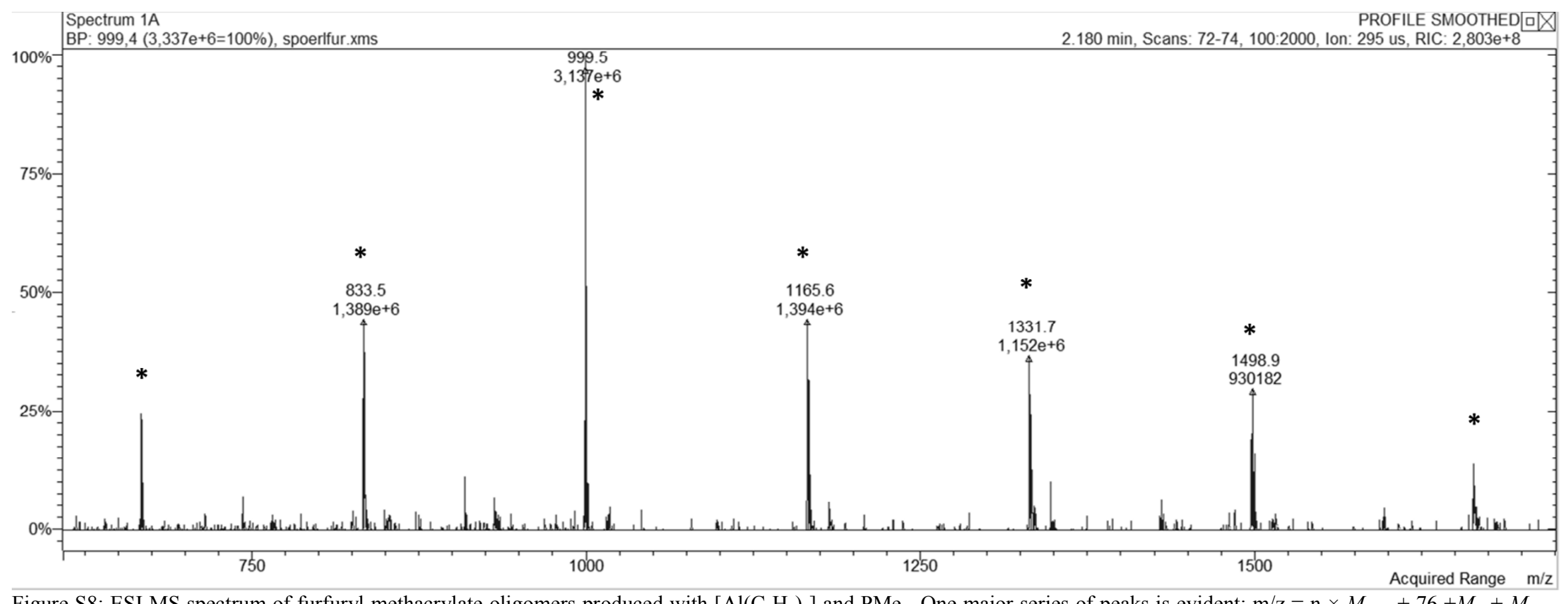

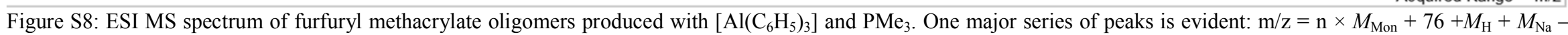
$M_{\mathrm{OFur}}(*) ; M_{\mathrm{Mon}}=166, M_{\mathrm{OFur}}=97$, end groups: $M_{\mathrm{PMe}_{3}}=76$. 


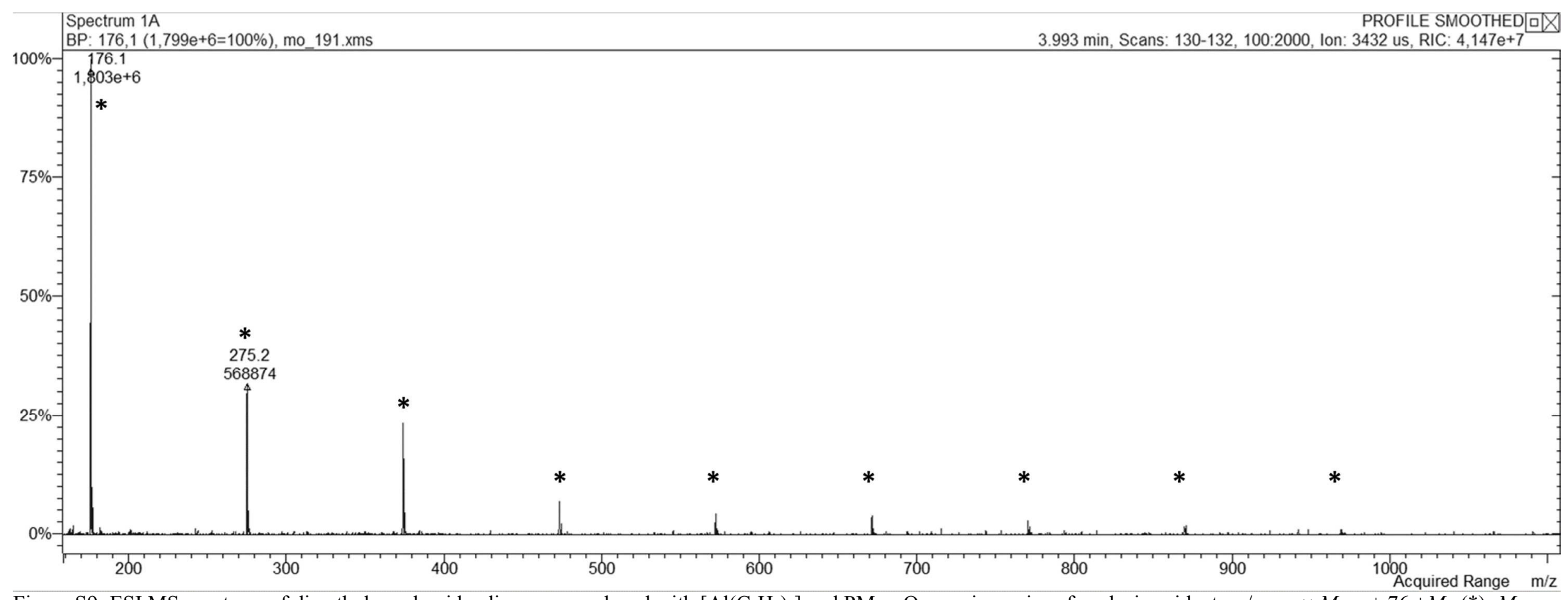

Figure S9: ESI MS spectrum of dimethyl acrylamide oligomers produced with $\left[\mathrm{Al}\left(\mathrm{C}_{6} \mathrm{H}_{5}\right)_{3}\right]$ and $\mathrm{PMe}_{3}$. One major series of peaks is evident: $\mathrm{m} / \mathrm{z}=\mathrm{n} \times M_{\text {Mon }}+76+M_{\mathrm{H}}(*) ; M_{\text {Mon }}=$ 99 , end groups: $M_{\mathrm{PMe}_{3}}=76$.

[1] Y. Zhang, G. M. Miyake, M. G. John, L. Falivene, L. Caporaso, L. Cavallo, E. Y.-X. Chen, Dalton Transactions 2012, 41, 9119-9134. 